\title{
PADA GELAHANG: SUATU PERKAWINAN ALTERNATIF DALAM MENDOBRAK KEKUATAN BUDAYA PATRIARKI DI BALI
}

\author{
I Nyoman Pursika ${ }^{1}$, Ni Wayan Arini ${ }^{2}$ \\ 1Jurusan PPKn, Fakultas IImu Sosial, Universitas Pendidikan Ganesha, \\ Singaraja, Indonesia \\ 2Jurusan PGSD, Fakultas IImu Pendidikan, Universitas Pendidikan Ganesha, \\ Singaraja, Indonesia \\ e-mail: pursika@ymail.com
}

\begin{abstract}
Abstrak
Tujuan penelitian ini adalah (1) menganalisis persepsi masyarakat terhadap perkawinan pada gelahang sebagai perkawinan alternatif di Provinsi Bali, (2) menganalisis sistem pewarisan dalam perkawinan pada gelahang bagi laki-laki dan perempuan, (3) menganalisis pola pengasuhan anak dalam perkawinan pada gelahang, (4) menganalisis proses pelaksanaan perkawinan pada gelahang, (5) menganalisis persamaan dan perbedaan pelaksanaan perkawinan pada gelahang dengan perkawinan nyentana. Penelitian ini menggunakan pendekatan Etnography Research dalam paradigma penelitian kualitatif. Penelitian ini dilakukan di Provinsi Bali. Persepsi masyarakat Bali terhadap perkawinan pada gelahang termasuk positif, karena dipandang sebagai realitas yang sudah ada di masyarakat, dan tidak pernah dipersoalkan. Sistem pewarisan dalam keluarga yang melaksanakan perkawinan pada gelahang di Bali pada dasarnya menganut asas parental, yaitu sistem pewarisan yang mewarisi pihak keluarga laki-laki dan keluarga perempuan. Pola pengasuhan anak dalam keluarga yang terbentuk melalui perkawinan pada gelahang pada umumnya memilih pola asuhan demokratis yang dicirikan dengan adanya hak dan kewajiban orang tua dan anak adalah sama, dalam arti mereka saling melengkapi. Proses pelaksanaan perkawinan pada gelahang tidak berbeda dengan proses perkawinan biasa, dan pada umumnya dilaksanakan dengan proses meminang, yang sebelumnya diawali dengan masa pacaran. Dalam perkawinan pada gelahang ada dua kali upacara yang relatif sama, yaitu di rumah kediaman mempelai laki-laki dan di rumah kediaman mempelai perempuan. Persamaan perkawinan pada gelahang dengan perawinan nyentana yaitu: sama-sama merupakan perkawinan alternatif, didasarkan cinta sama cinta, ada saksi agama (banten upacara) dan saksi sosial (masyarakat) dan sama-sama ingin mendapatkan keturunan. Sedangkan perbedaannya adalah bahwa perkawinan pada gelahang status lakilaki dan perempuan tidak ada perubahan status, sehingga sering disebut parental. Kedudukan anak-anak yang dilahirkan dimiliki secara bersama-sama, kecuali ada perjanjian lain. Aspek penting dalam perkawinan pada gelahang yang jarang ditemui adalah ada kesepakatan antara suami dan istri yang disaksikan oleh keluarga kedua belah pihak, perjanjian tersebut bisa tertulis dan bisa lisan.
\end{abstract}

Kata kunci: perkawinan pada gelahang, nyentana, patriarki, parental. 


\begin{abstract}
This study aims at analyzing (1) the perception of the society toward pada gelahang marriage system as an alternative form of marriage in Bali, (2) the system of inheriting in pada gelahang marriage system for the bridegroom and bride, (3) the system of taking care of the children, (4) the process of the implementation of pada gelahang marriage system, (5) the difference and the similarity of pada gelahang marriage system and nyentana (the bridegroom lives at the bride house). This study used Ethnography research in paradigm of qualitative research. This reaserch was done in Bali. The results of the study show that the perception of the society in Bali toward pada gelahang marriage system is positive because is has been viewed as reality in society, and it has never been a problem. The system of inheriting is based on parental principle, namely, the inheritance system can be both man family and woman family. The system of taking care of the children follows democratic system which is chatacterized by the right and duty of parents and children are equal in terms of they must complete each other. The process of pada gelahang marriage system is not so different from the process of marriage in general, that is, it is done by meminang (marriage by request). There are two ceremonies in pada gelahang marriage system which are relative the same as in the bridegroom house and the bride house. The similarity of pada gelahang marriage system and nyentana are the same as an alternative marriage, namely, marriage which is based on love and it also has religious witness (offering ceremony), and social witness. Both types of marriage want to get generation. The difference between pada gelahang and nyentana marriage system is that there is no changing status of the bridegroom and the bride. Therefore, it is often called parental. The position of children belongs to bridegroom and the bride, except there is a certain agreement. The important aspect of pada gelahang marriage system is there is an agreement between husband and wife wich is testified by both family. The agreement could be written and oral form.
\end{abstract}

Keywords: pade gelahang marriage, nyentana, patriarki, parental.

\section{PENDAHULUAN}

Undang-Undang No.1 Tahun 1974 tentang Perkawinan menyatakan bahwa perkawinan adalah ikatan lahir bathin antara seorang pria dengan seorang wanita sebagai suami istri dengan tujuan membentuk keluarga (rumah tangga) yang bahagia dan kekal berdasarkan Ketuhan-an Yang Maha Esa. Ada beberapa sistem kekeluargaan dalam masyarakat. (1) Sistem kekeluargaan patrilineal, yaitu sistem kekeluargaan yang didasarkan atas pertalian darah menurut garis bapak. Dalam sistem ini si isteri akan menjadi warga masyarakat dari pihak suaminya. (2) Sis-tem kekeluargaan matrilineal, yaitu sistem kekeluargaan yang didasarkan atas perta- lian darah menurut garis ibu. Dalam sistem ini si isteri tetap tinggal dalam klan atau golongan keluarganya.

Pada umumnya masyarakat Bali menganut sistem perkawinan patrilineal, yang mengambil bentuk perkawinan biasa atau perkawinan nyentana. Dalam perkawinan biasa, si gadis meninggalkan rumahnya dan diajak ke rumah keluarga pengantin laki-laki. Sedangkan dalam perkawinan nyentana, mempelai laki-laki yang statusnya berubah menjadi perempuan (predana) ikut pada keluarga mempelai wanita yang telah dikukuhkan sebagai laki-laki (purusa). Tujuan pokok dari perkawinan nyentana adalah untuk mengusahakan agar sang istri (selaku anak 
perempuan) memperoleh kedudukan selaku sentana purusa (laki-laki) atau pelanjut keturunan dalam lingkungan keluarganya. Dalam sistem purusa, anak perempuan biasanya merupakan sentana yang berstatus lemah atau labil, tak dapat tegak di rumah asalnya. Karena itu dengan perkawinan nyentana selaku sara-na, maka sentana perempuan itu dikukuh-kan (dirajegkan) sebagai laki-laki (purusa). Dengan demikian sentana rajeg berarti anak perempuan selaku sentana yang biasanya tidak kuat, dengan dan melalui perkawinan nyentana selaku rajegnya, dijadikan sentana yang kokoh berstatus purusa. Singkatnya sentana yang lemah diberi rajeg supaya kokoh.

Selain bentuk perkawinan di atas, di Bali juga dikenal bentuk perkawinan pada gelahang, yaitu perkawinan antara laki-laki dan perempuan yang sama-sama bersta-tus purusa (laki-laki). Menurut Sudarsana (dalam Windia 2009) bahwa perkawinan pada gelahang di beberapa tempat disebut dengan istilah yang berbeda-beda. Di Banjar Poh Manis Penatih, Denpasar disebut dengan negen dadua, di Banjar Kukub, Perean, Tananan disebut mapa-nak bareng, di Desa Belumbang, Keram-bitan, disebut nadua umah. Walaupun penyebutan berbeda-beda, namun makna yang terkandung dari sebutan itu adalah perkawinan pada gelahang atau gelahang bareng (miliki bersama). Lebih lanjut Sudarsana menjelaskan perkawinan pada gelahang ini sangat didasarkan oleh kekerabatan yang sama, karena waris pewaris dikemudian hari. Perkawinan pada gelahang adalah perkawinan yang dilakukan oleh pasangan suami istri yang upacara pabeyakaonan (sahnya perkawin-an) dilakukan di tempat kediaman masingmasing pasangan. Perkawinan pada gelahang menganut sistem parental, karena hak dan kewajiban laki-laki dengan perempuan sama (seimbang). Alasan utama dilaksanakan perkawinan pada gelahang adalah karena laki-laki (purusa) tidak mau diubah statusnya menjadi perempuan (pradana). Perkawinan pada gelahang dapat menyelamatkan keturunan bagi mereka yang tidak memiliki anak laki-laki, manakala mempelai laki-laki juga tidak berkenan untuk nyentana. Secara sederhana dapat dikatakan bahwa penye-bab utama munculnya model perkawinan ini karena ada satu keluarga yang memiliki anak perempuan saja dan pihak laki-laki tetap menginginkan agar berstatus purusa, karena terikat dengan tanggung jawab. Perkawinan seperti ini memiliki landasan hukum yang kuat, seperti termuat dalam Weda dan Susastra Hindu lainnya. Perkawinan model ini sejalan dengan penghormatan terhadap perempu-an sebagaimana terdapat dalam kitab suci Weda (perspektif gender) maupun perspektif nilai-nilai kemanusiaan.

Tujuan penelitian ini adalah: (1) menganalisis persepsi masyarakat terhadap perkawinan pada gelahang sebagai perkawinan alternatif di Provinsi Bali, (2) menganalisis sistem pewarisan dalam perkawinan pada gelahang bagi laki-laki dan perempuan, (3) menganalisis pola pengasuhan anak dalam perkawinan pada gelahangi, (4) menganalisis proses pelaksanaan perkawinan pada gelahang, dan (5) menganalisis persamaan dan perbeda-an pelaksanaan perkawinan pada gelah-ang dengan perkawinan nyentana.

\section{METODE}

Penelitian ini menggunakan pendekatan Etnography Research dalam paradigma penelitian kualitatif. Penelitian ini 
dilakukan di Provinsi Bali. Subjek peneliti-an ini terdiri dari: 1) pasangan perkawinan (lakiperempuan) pada gelahang, 2) apa-ratur pemerintah desa dinas dan pengurus (prajuru) desa pakraman, dan 3) masyarakat etnis Hindu, yang ditentukan secara purposive. Sesuai dengan jenis data yang diperlukan, maka pengumpulan data da-lam penelitian menganut prinsip Human Instrument, yaitu peneliti merupakan instrumen penelitian yang utama Carspecken (1998). Namun, dalam pelaksanaannya, peneliti juga akan mengguna-kan beberapa instrumen dan teknik pe-ngumpul data, yaitu: wawancara menda-lam, observasi dan pencatatan dokumen. Analisis data dilakukan dengan analisis kualitatif.

\section{HASIL DAN PEMBAHASAN}

Persepsi masyarakat terhadap perkawinan pada gelahang pada dasarnya berada dalam kategori positif, karena faktanya sudah banyak dilakukan oleh masyarakat, dan sesuai dengan sastra suci Hindu. Sistem pewarisan dalam keluarga yang melaksanakan perkawinan pada gelahang di Bali pada dasarnya menganut asas parental, yaitu sistem pewarisan yang mewarisi pihak keluarga laki-laki dan keluarga perempuan secara bersama-sama (seimbang). Sistem ini menggambarkan terjadinya pergeseran dari sistem patrilineal ke sistem parental. Perubahan ini didasarkan pada kemajuan pendidikan masyarakat, sehingga lebih mengedepankan kesetaraan, kepekaan, keadilan gender, kesadaran akan penghargaan harkat dan martabat manusia, termasuk kesadaran dalam melaksanakan hak asasi manusia (HAM). Menenai pola pengasuhan anak dalam keluarga yang terbentuk melalui perkawinan pada gelahang di Bali pada umumnya memilih pola asuhan demokratis yang dicirikan dengan adanya hak dan kewajiban orang tua dan anak adalah sama, dalam arti mereka saling melengkapi. Hal ini ditegaskan oleh I Nyoman Nada (pasangan yang melangsungkan perkawinan Pada Gelahang). Dalam keluarga Bapak I Nyoman Nada, secara perlahan tetapi pasti mengajak anak-anaknya untuk bertanggung jawab dan menentukan perilaku sendiri untuk mencapai kedewasaan. Tindakan dan perilaku Bapak I Nyoman Nada selalu disampaikan dengan alasan dan tujuan untuk saling membantu dan saling penuh pengertian.

Proses upacara (pabyakaonan) dalam perkawinan pada gelahang dilaksanakan di dua tempat, yaitu di rumah kediaman istri dan di rumah kediaman suami, yang sama-sama dihadiri oleh keluarga dan masyarakat.

Di sisi lain, perkawinan nyentana juga dinilai sebagai salah satu bentuk perkawinan alternatif yang bisa menyelamatkan keluarga-keluarga yang tidak memiliki anak laki-laki. Dengan mengambil bentuk perkawinan nyentana, anak perempuan dapat dikukuhkan statusnya sebagai laki-laki (purusa) yang dapat meneruskan keturunan, sehingga mereka dapat terhindar dari keluarga putus (cepung). Meskipun demikian, keputusan untuk melakukan perkawinan nyentana harus dipertimbangkan terlebih dahulu secara matang oleh keluarga-keluarga nyentana. Selain mempertimbangkan unsur sama-sama cinta, pihak mempelai laki-laki juga harus mempertimbangkan untuk melepaskan status laki-laki (purusa) dan menerima status sebagai perempuan (predana). Demikian juga pihak mempelai 
perempuan harus mempertimbangkan untuk menerima status sbagai purusa.

Motivasi utama pihak laki-laki yang umumnya masih keluarga besar mau melaksanakan sistem perkawinan nyen-tana adalah karena alasan cinta. Karena cintanya itulah pihak laki-laki mau ber-korban untuk membantu keluarga calon istrinya, yang umumnya masih kerabatnya agar terhindar dari keluarga cepung. Ada juga keluarga nyentana yang tidak berasal dari kerabat dekat mau nyentana dengan alasan yang tidak jauh berbeda dengan mereka yang masih ada hubungan kerabat, yaitu ingin membantu keluarga calon istrinya agar tidak menjadi keluarga cepung. Hanya saja, mereka mengalami lebih banyak tekanan dari pihak keluarga-nya sebelum memutuskan untuk melang-sungkan perkawinan nyentana. Tekanan itu bahkan tidak jarang memutuskan tali persaudaraan antara pihak laki-laki dengan keluarga asalnya untuk sementara waktu. Pihak lakilaki tidak bisa menghin-dar dari perkawinan nyentana, karena pihak keluarga perempuan umumnya bertahan ingin menjadikan anak perempu-annya menjadi sentana rajeg yang dapat meneruskan keturunan berdasarkan prin-sip patrilinial. Karena itu, demi cintanya pihak laki-laki bersedia berkorban menjadi berstatus dan berkedudukan sebagai predana dalam keluarga istrinya. Sebagai konsekuensinya, ia bisa turun kelas wang-sanya (dari perkawinan nyentana beda wangsa), tidak memiliki hak waris di keluarga istrinya, dan ia juga kehilangan hak waris di keluarganya asalnya, karena sudah meninggalkan keluarga dan ber-status predana. la juga tidak lagi memba-ngun kerabat dalam garis keturunan laki-laki (patrilinial), melainkan membangun kerabat dari garis keturunan matrilinial. Motivasi pengorbanan seperti di atas, maka pihak laki-laki juga biasanya mempertimbangkan tingkat kehormatan keluarga perempuan dalam masyakat sebelum memutuskan untuk melaksana-kan perkawinan nyentana. Lakilaki umumnya bersedia melakukan perkawin-an nyentana jika calon istri dan keluarga-nya merupakan orang-orang yang terhor-mat status dan kedudukannya di masyara-kat. Keterhormatan tersebut bisa dari berbagai sumber, antara lain: terhormat karena ketokohannya, kharismanya, latar pendidikan dan pekerjaannya, sikap dan perbuatan yang baik di masyarakat, dan bisa juga karena pemilikan harta warisannya yang banyak. Motivasi ini tidak sama sekali menghilangkan motivasi cinta dan pengorbanan dari laki-laki sebagai motivasi utama melangsungkan sistem perkawinan nyentana. Motivasi ini meleng-kapi motivasi utamanya, karena dimaksud-kan untuk tetap dapat memberikan pihak laki-laki status dan kedudukan terhormat baik di keluarga asalnya maupun di masyarakat keluarga istrinya.

Sebaliknya, meskipun motivasi pihak perempuan melakukan perkawinan nyentana juga dilandasi rasa cinta, namun ia lebih mencintai dan menghormati kepentingan keluarganya. Anak perempu-an dalam keluarga yang menginginkan perkawinan nyentana umumnya telah dididik sejak awal agar ia patuh serta menghormati kedua orangtua dan keluar-ganya. Karena itu, perempuan seperti ini biasanya sangat menjadi tumpuan dan harapan keluarga. la mempunyai nilai yang amat tinggi dalam keluarganya, baik secara sosial budaya dan ekonomi mau-pun sebagai penerus keturunan. Perem-puan seperti ini dalam keluarga biasanya telah dididik untuk bisa berstatus dan berkedudukan terhormat seperti anak laki-laki umumnya di Bali.

Jurnal IImu Sosial dan Humaniora | 72 
Melalui pendidikan seperti itu ia merasa sangat berhutang budi dan merasa tidak bisa meninggalkan keluarganya dan merasa wajib melindungi kepentingan keluarganya. Perempuan se-perti ini cenderung dijuluki sebagai perempuan yang berpikir rasional dalam memaknai cinta kepada lawan jenisnya.

Pengelolaan keluarga perkawinan nyentana sesungguhnya tidaklah mengubah seluruh status laki-laki menjadi perempuan. Keluarga nyentana pada umumnya adalah juga keluarga yang menerapkan budaya patriarkhi di lingkungan rumah tangga dan masyarakatnya. Bedanya keluarga ini tinggal menetap secara matrilokal dan perempuanlah sebagai purusa di keluarga nyentana yang memiliki hak-hak istimewa atas warisan keluarganya. Di sini laki-laki sebagai ayah tetap menjalankan tugas-tugas dan peran di sektor publik sedangkan istri sebagai ibu tetap menjalankan tugas-tugas dan peran perempuan di sektor domestik. Pembagian tugas dan peran seperti ini sudah menjadi budaya patriarki yang kuat di Bali. Laki-laki, misalnya, tetap menjalan-kan peran sebagai pencari nafkah utama dalam keluarga seperti bertani di sawah, menjadi tukang bangunan, menjadi pe-ngrajin ukiran kayu, menjadi pengrajin anyaman bambu, menjadi pegawai negeri, dan sebagainya. Pengambilan keputusan dalam keluarga juga masih didominasi oleh laki-laki, kecuali yang menentukan keberadaan dan penggunaan warisan keluarga. Laki-laki juga mewakili keluarga dalam menunjukkan partisipasi sosial, politik, budaya, dan religiusnya baik kepada desa pekraman maupun kepada desa dinas. Laki-lakilah yang mewakili keluarga dalam sangkepan (musyawarah) yang dilaksanakan di desa pekraman tentang hak-hak dan kewajiban sebagai kerama desa (warga desa). Lakilaki juga yang melakukan gotong royong untuk kepentingan pelaksanaan perwujudan nilai-nilai tri hita karana di lingkungan desa pekraman, baik yang mencakup pengelolaan parahyangan (unsur hubungan manusia dengan Tuhan Yang Maha Esa), pawongan (unsur hubungan sosial sesa-ma warga desa pekraman), maupun pengelolaan unsur palemahan (unsur hubungan manusia dengan lingkungan alam baik secara sekala maupun niskala). Perempuan dalam hal ini bersifat membantu melengkapi beberapa kewajiban terutama untuk unsur parahyangan dan pawongan. Dalam hal pendidikan anak sekali pun keluarga nyentana masih menerapkan prinsip budaya patriarkhi. Walaupun status laki-laki dalam perka-winan nyentana telah putus hubungannya dengan keluarga asalnya karena sudah dipinang keluarga perempuan, tidak berarti bahwa hubungan antara si laki dengan kedua orangtuanya dan dengan saudara-saudara asalnya serta kerabat-nya putus sama sekali baik secara sekala maupun niskala. Hubungan kekeluargaan itu tetap berlangsung seperti semula, walau tidaklah bersifat wajib.

Walau telah terjadi perubahan status, kedudukan, serta hak dan kewajib-an laki-laki dalam keluarga dengan perka-winan nyentana, dalam hal pembagian tugas dan peran dalam keluarga dan masyarakat ternyata tidak terdapat perbe-daan dengan keluarga perkawinan patri-linial pada umumnya. Tugas dan peran laki-laki dan perempuan dalam perkawin-an nyentana ternyata sama saja dengan tugas dan peran di perkawinan patrilinial yang berbasis pada pembagian tugas dan peran dalam keluarga dan masyarakat dengan budaya patriarkhi. Kesamaan tugas dan peran ini dimaksudkan

Jurnal IImu Sosial dan Humaniora | 73 
untuk menjaga keseimbangan dan keharmonis-an dalam keluarga dan masyarakat yang berbudaya patriarki di Bali pada umum-nya.

Persamaan dan perbedaan
perkawinan pada gelahang dengan
perkawinan nyentana dapat dilihat dalam
tabel berikut ini.

Tabel 1. Persamaan dan Perbedaan Perkawinan Pada Gelahang dengan Perkawinan Nyentana

\begin{tabular}{ll}
\hline Perkawinan Pada Gelahang & Perkawinan Nyentana \\
\hline$>$ Sebagai perkawinan alternatif yang banyak & $>$ Sebagai perkawinan alternatif yang banyak \\
diminati masyarakat Bali
\end{tabular}

\section{PEMBAHASAN}

Perkawinan pada gelahang seba-gai perkawinan alternatif yang telah lama ada, dan semakin diminati oleh masyara-kat Bali. Pandangan tersebut mengandung makna bahwa secara sosiologis masyara-kat melihat bahwa perkawinan pada gelahang sebagai realitas di masyarakat. Secara antropologis, masyarakat meman-dang bahwa perkawinan pada gelahang sebagai warisan budaya yang perlu diles-tarikan dan tidak perlu dipertentangkan. Secara yuridis, perkawinan pada gelahan telah sesuai dengan santra agama (Hukum Hindu) dan Undang-Undang No.1 Tahun 1974 tentang Perkawinan. Perka-winan pada gelahang berbeda dengan perkawinan yang selama ini dilaksanakan oleh masyarakat Bali, yang 
menganut sistem patrilineal (garis kepabaan/purusa). Perkawinan pada gelahang menerapkan sistem parental, karena menempatkan perempuan dan lakilaki setara. Ini berarti terjadi pergeseran dari sistem kekeluarga-an patrilineal ke sistem parental. Sistem kekeluargan di sini diartikan sebagai cara menarik garis keturunan, sehingga dapat diketahui dengan siapa seseorang mem-punyai hubungan hukum kekeluargaan. Kita sadari bersama bahwa sistem keke-lurgaan yang berlaku dalam masyarakat di Indonesia sangat beragam, yang disebab-kan oleh adanya multi etnis, multi agama, multi budaya dan sebagainya, sehingga menyulitkan pembentukan hukum keluar-ga nasional. Sebagaimana diketahui bah-wa tujuan utama dari perkawinan pada gelahang adalah untuk melahirkan keturunan jangan sampai putus (cepung). Hal ini dimaksudkan untuk mengatasi kekhawatiran tentang warisan yang ditinggalkan oleh orang tua, baik yang berwujud kewajiban maupun hak ada yang mengurus atau meneruskan.

Konskuensi logis perkawinan pada gelahang adalah perubahan status kekeluargaan dari kebapaan/purusa menjadi kebapaan dan ibu secara bersama-sama, yang sering disebut parental. Dalam arti bahwa suami dan istri mempunyai hak dan kewajiban yang sama baik di rumah suami dan di rumah si istri sehingga sering disebut tanggung bersama-sama (negen dadua). Demikian juga status anak-anak/keturunan mempunyai kewajiban dan hak sama baik di rumah kediaman ibunya dan di rumah kediaman bapaknya. Hak hak dan kewajiban itu dapat berupa penerus keturunan, sebagai ahli waris, dan bertanggung jawab terhadap tempat sembahyang yang ada di rumah ibunya dan di rumah bapaknya.
Meningkatnya kecenderungan masyarakat Bali melaksanakan perkawinan pada gelahang, sebagai perkawinan alternatif, telah diperkuat dengan Paruman Sulinggih dan Paruman Walaka Pengurus Parisada Hindu Dharma Indonesia Provinsi Bali yang menegaskan bahwa perkawinan pada gelahang sesuai dengan ajaran agama Hindu dan Hukum Adat Bali. Hal ini memberikan indikasi bahwa kesa-daran terhadap kesetaraan dan keadilan gender, penghargaan terhadap harkat dan martabat manusia, penghargaan terhadap hak asasi manusia (HAM), serta kesadar-an untuk mendapat keturunan untuk mewarisi warisan berupa material dan immaterial semakin meningkat.

\section{SIMPULAN DAN SARAN}

Perkawinan pada gelahang sudah menjadi suatu kenyataan pada masyara-kat, khususnya di Bali. Saat ini, ada kecenderungan semakin banyak masyarakat memilih perkawinan pada gelahang sebagai perkawinan alternatif untuk mendapatkan keturunan sebagai pelanjut keluarga. Sistem pewarisan dalam keluar-ga yang melaksanakan perkawinan pada gelahang pada dasarnya menganut asas parental, yaitu sistem pewarisan yang mewarisi pihak keluarga laki-laki dan keluarga perempuan secara bersama-sama (seimbang). Sistem pewarisan parental mengindikasikan terjadi pergeseran dari patrilineal ke parental. Kemajuan dalam bidang sosial (pendidikan) membuka cara berpikir masyarakat menuju kepada kesetaraan dan keadilan gender, kesadaran akan penghargaan harkat dan martabat manusia, termasuk kesadaran dalam melaksanakan hak asasi manusia (HAM). Pola pengasuhan anak dalam keluarga yang terbentuk melalui perkawinan pada 
gelahang pada umumnya memilih pola asuhan demokratis yang dicirikan dengan adanya hak dan kewajiban orang tua dan anak adalah sama dalam arti mereka saling melengkapi.

Proses perkawinan pada gelahang tidak jauh berbeda dengan proses perkawinan biasa, yaitu dilaksanakan dengan proses meminang/memadik, yang sebelumnya diawali dengan masa pacaran. Proses upacara dalam perkawinan biasa, umumnya keluarga laki-laki relatif lebih sibuk bila dibandingkan dengan keluarga perempuan. Sedangkan proses upacara perkawinan pada gelahang relatif seim-bang antara pihak keluarga laki-laki dan pihak keluarga perempuan. Keseimbang-an ini ditandai dengan adanya upacara yang sama di rumah mempelai laki-laki dan mempelai perempuan. Artinya, dalam perkawinan pada gelahang ada dua kali upacara yang relatif sama, antara di rumah mempelai lakilaki dan di rumah mempelai perempuan.

Pesamaan perkawinan pada gelahang dengan perawinan nyentana yaitu: sama-sama merupakan perkawinan alternatif, didasarkan cinta sama cinta, ada saksi agama (banten upacara) dan saksi sosial (masyarakat), dan sama-sama ingin mendapatkan keturunan. Sedangkan perbedaannya adalah bahwa perkawinan pada gelahang status laki-laki dan perempuan sama sehingga sering disebut parental. Kedudukan anak-anak yang dilahirkan sama-sama (seimbang/tidak memihak salah satu dalam konteks garis keturunan). Proses upacara perkawinan dilakukan di rumah suami dan di rumah istri. Aspek penting dalam perkawinan pada gelahang yang jarang ada pada perkawinan biasa adalah ada kesepakatan antara suami dan istri yang disaksikan oleh keluarga kedua belah pihak. Kesepakatan itu bisa tertulis dan bisa lisan dengan saksi keluarga.

\section{DAFTAR PUSTAKA}

Bagus. I Gustu Ngurah. 1971. Sistem Pola Menetap Masyarakat Bali. Denpasar: UNUD Denpasar.

Carspecken, P.F. 1998. Critical Ethno-grapy in Educational Research: A theoritical and practical guide. London and New York: Routledge.

Depdagri. 1992. Pembinaan Lembaga Adat di Desa dan Kelurahan, Jakarta: Depdagri.

Danandjaja, James. 1977. Pengasuhan Anak, Kebudayaan Desa Trunyan di Bali, Jakarta: Disertasi F.S UI.

Harian Umum Bali Post, Tanggal 20 Juli 2008: "Negen Dadua Mapanak Bareng Alternatif Perkawinan di Bali"

Harian Umum Bali Post, Tanggal 10 Oktober 2008: "Dianggap Tidak Sah, Perkawinan "'Negen" Digugat Ibu Tiri"

Harian Umum Bali Post, Tanggal 13 Oktober 2008: "Perkawinan "Negen" Sah dalam Hukum Hindu.

Kaler, I G.K. 1983. Butir-Butir Tercecer tentang Adat Bali (2) Denpasar: Bali Agung.

MPLA Daerah Tingkat I Bali. 1998. Hasilhasil Pesamuhan Pembina Desa Adat Daerah Tingkat I Bali tanggal 20 Maret 1998, Depasar: MPLA.

Miles M.B and Huberman, A.B. 1992. Analisis Data Kualitatif (Terj). Jakarta: UI Press.

Moleong, L.J. 1998. Metodologi Penelitian Kualitatif, Bandung: Remaja Rosda Karya.

Panetje. Gde. 1989. Aneka Catatan tentang Hukum Adat Bali. Denpasar: Guna Agung.

Pitana, I Gede. 1994. Desa Adat dalam Arus Modernisasi. Editor. Dinamika Masyarakat dan Kebudayaan Bali, Denpasar: Bali Post.

Pursika, I.N. 2008. Perempuan Berstatus Purusa (Analisis Proses, Kedudukan,

Jurnal IImu Sosial dan Humaniora | 76 
Konflik, Pewarisan, dan Pengasuhan Anak di Bali). Laporan Penelitian. Singaraja: Undiksha.

Windia, Wayan P. 2009. Perkawinan Pada Gelahang di Bali. Denpasar: Udayana University Press. 